\title{
Traveling 10-day Waves at Mid-latitudes in the Troposphere and Lower Stratosphere Revealed by Radiosonde Observations and MERRA-2 Data in 2020
}

Chunming Huang ( $\sim$ huangcm@whu.edu.cn )

Wuhan University

Lingyun Yang

Wuhan University

Shaodong Zhang

Wuhan University

Kaiming Huang

Wuhan University

Yun Gong

Wuhan University

Zheng Ma

Wuhan University

Jian Zhang

China University of Geosciences

\section{Research Article}

Keywords: Traveling 10-day waves, Troposphere and lower stratosphere, Middle atmosphere dynamics

Posted Date: January 12th, 2022

DOI: https://doi.org/10.21203/rs.3.rs-1238099/v1

License: (c) (1) This work is licensed under a Creative Commons Attribution 4.0 International License. Read Full License 


\section{Abstract}

Although the characteristics of the traveling 10-day waves (10DWs) above the middle stratosphere have been well explored, little research has been performed on the counterpart in the troposphere and lower stratosphere (TLS). In the present study, we use radiosonde observations and MERRA-2 data in 2020 to characterize traveling 10DWs in mid-latitudes in the TLS. Single-site observations in both hemispheres show that strong 10DW activities are always accompanied by strong eastward jets (10-13 km). MERRA-2 data indicates that in the troposphere the eastward-propagating modes with larger wavenumbers, i.e., E3, E4, E5 and E6 are dominant. While in the lower stratosphere the eastward- and westward-propagating modes with small zonal wavenumbers e.g., 1 and 2, are dominant. Further research on E3, E4, E5 and E6 modes in the troposphere of both hemispheres shows that all the wave activities are positively correlated to the background zonal wind. The refractive index squared reveal that a strong eastward jet is suitable for these four modes to propagate. However, just above the jet, the eastward wind decreases with altitude, and a thick evanescence region emerges above $15 \mathrm{~km}$. E3, E4, E5 and E6 10DWs cannot propagate upward across the tropopause; as such this can explain why these four modes are weak or even indiscernible in the stratosphere and above. In the troposphere, E5 10DW at $32^{\circ} \mathrm{S}$ is the most dominant mode in 2020. A case study of the anomalously strong E5 10DW activity on May 12, 2020 indicates that the wave amplification resulted from the upward and equatorward transmission of wave energy flows. Moreover, the tropopause and equatorial region can prevent the propagations of wave energy flows of E5 10DW.

\section{Introduction}

Atmospheric waves, including planetary waves (PWs), gravity waves (GWs) and tides (Forbes \& Garrett, 1979; Salby, 1984; Fritts \& Alexander, 2003), are periodic disturbances of the atmosphere with respect to the mean background state; these disturbances are detected in the fields of atmospheric meteorological parameters, e.g., the wind velocity, temperature, geopotential height and pressure. Atmospheric waves dominate throughout the atmosphere and play pivotal roles in determining local and global atmospheric variations and transient structures (Lieberman \& Hays, 1994; Alexander et al., 2010; Irving \& Simmonds, 2015).

PWs are large-scale atmospheric oscillations that can be divided into quasi-stationary PWs and traveling PWs (Hirooka, 1986; Pancheva et al., 2008), where the latter can be classified either as free modes or as forced waves. The free modes, also known as Rossby normal modes, can be obtained from the solutions of Laplace's tidal equation (Ahlquist, 1982). Free modes propagate westward with periods (zonal wavenumbers) near $2(s=3), 5(s=1), 10(s=1)$, and $16(s=1)$ days, and waves with these periods are often referred to as quasi-2-day waves (QTDWs), quasi-5-day waves (Q5DWs), quasi-10-day waves (Q10DWs), and quasi-16-day waves (Q16DWs), respectively (Salby, 1984). Normal modes with these typical periods have been observed in the stratosphere, mesosphere and lower thermosphere (Wu et al., 1994; Pancheva et al., 2004; McDonald et al., 2011; Forbes \& Zhang, 2015) and have been the topic of theoretical investigations for many decades (Ahlquist, 1982; Salby, 1984; Hirooka \& Hirota, 1985; Hirooka, 
1986; Salby \& Callaghan, 2001; Forbes \& Zhang, 2015). Interestingly, many scholars discovered that the actual wavefields associated with these quasi-periodic waves contain a number of other modes, e.g., the eastward-propagating modes and westward-propagating modes with zonal wavenumbers different from those of the abovementioned normal modes. These traveling modes also play key roles in and interact with other waves or the mean flow, thereby affecting atmospheric dynamics (Pancheva et al., 2004; palo et al., 2005; McDonald et al., 2011; John \& Kumar, 2016; Huang et al., 2021; Wang et al., 2021).

Compared with the research on other quasi-periodic PWs, investigations specifically considering traveling 10DWs have been relatively sparse, and almost all of these studies were focused on the stratosphere and above. For instance, the normal mode of the 10DW was clearly observed in the global stratosphere by using satellite observations, which suggested that it always persisted for 1-2 months and was stronger in the Northern Hemisphere (NH) than in the Southern Hemisphere (SH) (Hirooka \& Hirota, 1985). In addition, dominant 10DWs were detected in the mid-latitude lower ionosphere and were considered to be caused by PWs coming from below (Laštovička, 1996). lonospheric sounding data revealed that the Flayer electron density profiles were modulated by PW-type oscillations, e.g., modes with 2-day, 5-day, 10day and 16-day periods (Fagundes et al., 2005). As revealed by the Canadian Middle Atmosphere Model (CMAM), the normal mode of the 10DW is strongly correlated with variations in the chemical species between 30 and $60 \mathrm{~km}$ (Pendlebury et al., 2008). Moreover, PWs play an important role in ozone transport throughout the stratosphere. For instance, the 10DWs found in ozone profile data and medium-frequency radar (MFR) wind data were both consistent with the normal mode (Chen et al., 2011). Sounding of the Atmosphere using Broadband Emission Radiometry (SABER) temperature measurements were employed to provide a comprehensive perspective of the westward-propagating 10DW (zonal wavenumber of 1) between 20 and $100 \mathrm{~km}$ at latitudes of $50^{\circ} \mathrm{S}-50^{\circ} \mathrm{N}$ (Forbes \& Zhang, 2015). The W1, W2, E1 and E2 10DWs were studied in detail by using Thermosphere, lonosphere, Mesosphere, Energetics and Dynamics (TIMED) SABER observations, which are all strong at high latitudes and during winter (John \& Kumar, 2016). Moreover, the eastward-propagating 10DWs were found to be governed by different mechanisms from those responsible for the normal modes. Using the long-term Modern Era Retrospective-Analysis for Research and Applications version 2 (MERRA-2) database, Huang et al. (2021) found that W1, E1 and E2 $10 \mathrm{DWs}$ are the dominant traveling waves below the middle mesosphere, and reach their peaks near the stratopause. The E1 and E2 10DWs in the stratosphere might come from those downward-propagating waves excited in the mesosphere by the mean flow instability. Additionally, the enhanced PW activity in the middle atmosphere is a typical phenomenon during or after sudden stratospheric warming (SSW). Consequently, the association of 10DWs with SSW events has received some attention over the past two decades (Palo et al., 2005; Yu et al., 2019; Yamazaki \& Matthias, 2019; He et al., 2020; Luo et al., 2020; Wang et al., 2021), with researchers finding that enhanced 10DWs are closely related to SSW. Ultimately, the abovementioned studies demonstrated that the 10DW field in the stratosphere and above is dominated by modes with small zonal wavenumbers, i.e., W1, W2, E1 and E2.

Nevertheless, PWs in the troposphere and lower stratosphere (TLS), the main source region of atmospheric waves, have not been adequately studied. Baroclinic instability, the forcing action of zonally asymmetric heating, and topography could all serve as sources of PWs in the troposphere (Charney \& 
Drazin, 1961). It is worth noting that PWs in the TLS have greater wind amplitudes (usually larger than 10 $\mathrm{ms}^{-1}$ ) than tides and GWs and thus deserve more attention (Zhang et al.,2008; Huang et al., 2009; Wang et al., 2010). As such, a few studies involved the 10DWs in the TLS. As revealed by intensive radiosonde observations over Yichang $\left(111^{\circ} 18^{\prime} \mathrm{E}, 30^{\circ} 42^{\prime} \mathrm{N}\right)$, 10DWs can exert great impacts on the tropospheric jet in winter and the tropopause in both summer and winter months and can obviously modulate diurnal tidal amplitudes (Huang et al., 2009). The proximity of strong 10DWs near the tropospheric subtropical jet stream led some researchers to conclude that the jet stream strengthened the propagation of 10DWs and might even be their excitation source (Wang et al., 2012). Huang et al. (2017) studied the characteristics of PWs in the lower atmosphere over Xianghe $\left(117.00^{\circ} \mathrm{E}, 39.77^{\circ} \mathrm{N}\right)$, China, by utilizing Beijing mesospherestratosphere-troposphere (MST) radar measurements and found 10DWs and 16DWs displaying similar seasonal and height variations, implying the same excitation source; in addition, these waves exhibited prevailing eastward propagation in the meridional direction and a quasi-standing structure in the vertical direction. These studies revealed some local characteristics of 10DWs in the TLS. From the perspective of their temporal and spatial resolutions and height coverage, radiosonde and MST radar data are quite suitable for studying local PWs in the TLS. However, the limitations of these data are obvious: the spatial distributions of radiosondes and MST radar stations are incredibly sparse, and the amount of observation data from these sources is still insufficient. Certainly, data from such a limited number of observation sites cannot provide accurate zonal wavenumber information for 10DWs. Moreover, the above studies revealed the characteristics of 10DWs in the TLS of only the $\mathrm{NH}$. Accordingly, a number of unsolved questions remain, including the following: (1) What modes does the 10DW wavefield in the TLS contain? (2) Which mode of 10DWs is the dominant mode in the TLS? (3) Where and what are the sources of the 10DWs in the TLS? (4) What are the similarities and differences between the local characteristics of the 10DWs in the TLS in the $\mathrm{NH}$ and $\mathrm{SH}$ ?

To solve the above questions, we need not only local but also global observation data. Satellite observations with good altitude resolution are a good candidate. However, most satellites can provide high-precision observations only above the lower stratosphere (John \& Kumar, 2016). MERRA-2 provides the latest atmospheric reanalysis data from the modern satellite era (Gelaro et al. 2017). A variety of observations are assimilated in MERRA-2; as such, the database can provide relatively complete information on physical quantities such as horizontal wind and temperature in the TLS. In recent years, MERRA-2 data have been extensively used to reveal the global characteristics of atmospheric waves (Gong et al., 2019; Yamazaki \& Matthias, 2019; Luo et al., 2020; Huang et al., 2021). Hence, we devote this paper to addressing the above questions by combining radiosonde observations with MERRA-2 data.

In this paper, our main objective is to characterize the mid-latitudes 10DWs in the TLS of both the NH and the $\mathrm{SH}$ from both local and global perspectives. After exposing the local characteristics of the complex 10DWs in both hemispheres by using radiosonde observations, we reveal the characteristics of the dominant modes of traveling 10DWs in the TLS of both hemispheres by leveraging MERRA-2 data.

The datasets utilized in this paper are described in detail in the following section. The background zonal wind is presented in section 3. Local 10DWs revealed by radiosonde observations are illustrated in 
section 4. The dominant traveling 10-day modes are studied in section 5 . A case study of the most dominant mode in the $\mathrm{SH}$ is provided in section 6 . In the last section, we will give summary and conclusions of our investigation.

\section{Data Description}

The Integrated Global Radiosonde Archive (IGRA) consists of radiosonde and pilot balloon observations from more than 2,800 globally distributed stations. Until January 2018, IGRA provided atmospheric soundings, including pressure, temperature, humidity and wind measurements, at approximately 445 radiosonde sites across the globe. The sampling rate of a high-resolution radiosonde is $1 \mathrm{~s}$ or $2 \mathrm{~s}$, which correspond to a vertical resolution of approximately 5-10 m throughout the atmosphere. Synoptic radiosonde measurements are taken twice per day at 0000 and 1200 UTC (Guo et al., 2021). We choose the radiosonde observations at Santa Teresa $\left(-106.7^{\circ} \mathrm{W}, 31.9^{\circ} \mathrm{N}\right)$ and Perth Airport $\left(116.0^{\circ} \mathrm{E}, 31.9^{\circ} \mathrm{S}\right)$ to reveal the local characteristics of complex 10DWs in both hemispheres. The high-resolution radiosonde observations at Santa Teresa $\left(-106.7^{\circ} \mathrm{W}, 31.9^{\circ} \mathrm{N}\right)$ with a vertical resolution of $5 \mathrm{~m}$ are provided by the United States National Oceanic and Atmospheric Administration (NOAA). In addition, the University of Wyoming provides radiosonde observations at 93 high-resolution sites with a sampling rate of $1 \mathrm{~s}$ or $2 \mathrm{~s}$, including the Perth Airport site $\left(116.0^{\circ} \mathrm{E}, 31.9^{\circ} \mathrm{S}\right)$. For convenience, the raw data are linearly interpolated to a uniform vertical resolution of $50 \mathrm{~m}$.

MERRA-2 is the latest atmospheric reanalysis of the modern satellite era produced by the NASA Global Modeling and Assimilation Office (GMAO) (Gelaro et al. 2017). The MERRA-2 product "inst6_3d_ana_Nv" used in the present study consists of reanalyzed fields at four synoptic times (00 GMT, 06 GMT, 12 GMT, and $18 \mathrm{GMT}$ ) at 72 nominal pressure levels varying from $985 \mathrm{hPa}$ to $0.01 \mathrm{hPa}$ with a native resolution of $0.625^{\circ}$ longitude by $0.5^{\circ}$ latitude. The product includes data spanning longitudes from $180.0^{\circ} \mathrm{W}$ to $179.375^{\circ} \mathrm{E}$ and latitudes from $90.0^{\circ} \mathrm{S}$ to $90.0^{\circ} \mathrm{N}$. In this study, physical quantities of the eastward wind component $(U)$, northward wind component $(V)$, and air temperature $(T)$ are considered for the analysis.

\section{Background Mid-latitude Zonal Wind In The Tls}

PW activities are closely related to the background structure, especially the activity of the zonal-mean zonal wind. Before revealing the characteristics of the 10DWs at the two abovementioned radiosonde observation stations, we first present the background zonal winds at these two locations. To display the day-to-day variations in the background zonal wind, we adopt a sliding 30-day window with an increment of 1 day to extract the background zonal wind on the central date of each window; then, the temporally averaged zonal wind within each window is regarded as the background component. Since there exist time gaps in the utilized observation data, no calculation is attempted if fewer than 18 days of data are present in a given 30-day window.

As visualized in the left panels of Figure 1, the background zonal winds at Santa Teresa $\left(-106.7^{\circ} \mathrm{W}\right.$, $\left.31.9^{\circ} \mathrm{N}\right)$ and Perth Airport $\left(116.0^{\circ} \mathrm{E}, 31.9^{\circ} \mathrm{S}\right)$ deduced from the radiosonde observations show 
characteristics that are highly similar to those revealed by previous observations at mid-latitudes (Wang et al., 2012; Huang et al., 2017). In the troposphere, the background zonal wind manifests as a strong, predominantly eastward-propagating tropospheric jet at heights of approximately $10-13 \mathrm{~km}$ in spring and winter months in both hemispheres, reaching maximum values of $54.1 \mathrm{~ms}^{-1}$ at $12.1 \mathrm{~km}$ in April in the NH and $54.5 \mathrm{~ms}^{-1}$ at $11.9 \mathrm{~km}$ in August in the SH. The zonal wind increases with altitude from $3.5 \mathrm{~km}$ up to approximately $12-13 \mathrm{~km}$ and then decreases with altitude; this is the typical tropospheric zonal wind structure at mid-latitudes. In the tropospheric jet stream area in summer and autumn, the eastward background zonal winds in the $\mathrm{NH}$ are evidently weaker than those in the $\mathrm{SH}$. In the lower stratosphere, the westward background zonal wind mainly appears in summer with maximum values of $-24.1 \mathrm{~ms}^{-1}$ at $32 \mathrm{~km}$ in July in the $\mathrm{NH}$ and $-24.3 \mathrm{~ms}^{-1}$ at $30.1 \mathrm{~km}$ in January in the $\mathrm{SH}$. Compared to its counterpart in the $\mathrm{NH}$, the westward background zonal wind in the $\mathrm{SH}$ persists over a longer time.

For comparison, the background zonal winds deduced from the MERRA-2 data at the two grid nodes nearest the observation stations $\left(\left(-106.875^{\circ} \mathrm{W}, 32^{\circ} \mathrm{N}\right)\right.$ and $\left.\left(116.25^{\circ} \mathrm{E}, 32^{\circ} \mathrm{S}\right)\right)$ are also provided in the right panels of Figure 1. The background zonal winds deduced from the MERRA-2 data have similar spatial and temporal distributions to those deduced from the radiosonde observations. Nevertheless, slight differences are still observed.

\section{Mid-latitude Local 10dws In The Tls}

Previous studies revealed that PW-scale perturbations exist at the mid-latitudes in the TLS of the NH (Huang et al., 2009; Wang et al., 2012; Huang et al., 2017). Radiosonde observations allow us to study $\mathrm{PW}$-scale perturbations in the time domain. Accordingly, we perform a Lomb-Scargle periodogram analysis (Scargle, 1982) to identify the primary oscillations.

The frequency spectra of the zonal winds at each sampling height from the radiosonde observations at Santa Teresa $\left(-106.7^{\circ} \mathrm{W}, 31.9^{\circ} \mathrm{N}\right)$ and Perth Airport $\left(116.0^{\circ} \mathrm{E}, 31.9^{\circ} \mathrm{S}\right)$ are plotted in the left panels of Figure 2 (only values greater than $1 \mathrm{~ms}^{-1}$ are shown). At mid-latitudes in the TLS, three salient PW-scale perturbations are detected: the 16DW (12-20 days) (Huang et al., 2017), the 10DW (8-12 days) (Forbes \& Zhang, 2015) and an oscillation with a period of approximately 20-30 days (Luo et al., 2001). We aim to investigate 10DWs in this paper; however, the other oscillations might be within the scope of our future research. Significant 10DWs appear in two layers (5-15 km and 25-32 km), and these oscillations are stronger in the troposphere than in the lower stratosphere. In the $\mathrm{NH}$, the strongest spectral peak of 3.2 $\mathrm{ms}^{-1}$ is situated at $\sim 11 \mathrm{~km}$ with a period of 10.2 days; in the $\mathrm{SH}$, the strongest spectral peak of $4.2 \mathrm{~ms}^{-1}$ is located at $\sim 11 \mathrm{~km}$ with a period of 9.1 days.

For comparison, the Lomb-Scargle periodograms of the zonal winds deduced from the MERRA-2 data at the same grid nodes as mentioned above are also provided in the right panels of Figure 2 and exhibit similar spatial and temporal distributions to those deduced from the radiosonde observations. However, slight differences are detected. For instance, the radiosonde observation-derived spectral magnitude with a period of 10.2 days at $\sim 11 \mathrm{~km}$ in the $\mathrm{NH}$ is slightly weaker than that derived from the MERRA-2 data. In 
addition, the radiosonde-derived spectra above $25 \mathrm{~km}$ in the $\mathrm{SH}$ are slightly different from those obtained from the MERRA-2 data. In summary, we find significant 10DWs in the zonal winds.

The above Lomb-Scargle periodogram analysis shows that 10DWs exist in the zonal winds. To display the day-to-day variations in the 10DWs, we again adopt a sliding 30-day window with an increment of 1 day to extract the 10DWs on the central date of each window. Within each window, the time average and the linear trend are removed from the raw data as the background component. Then, the residuals are harmonically fitted within the period range from 8.0 to 12.0 days in increments of 0.5 days. Since 10DWs are quasiperiodic, they are classified using the period band from 8.0 to 12.0 days rather than a single period. The formula used for the fitting is as follows:

$$
f^{\prime}(t)=A \cos \left(\frac{2 \pi}{T} t-\theta\right)
$$

where $t$ is the time in days and $A, T$, and $\theta$ are the amplitude, period, and phase of the 10DWs, respectively. Since the utilized observation data contain time gaps, no fit is attempted if fewer than 18 days of data are present in a given 30-day window. The wave amplitude at any given height on the central date of each window corresponds to the one fit among these periods that has the largest amplitude. Moreover, because the data from a single sounding site cannot provide the zonal wavenumber information of 10DWs, the fitted amplitude corresponds to synthesized multimodal 10DWs, i.e., the superposition of multiple modes with different zonal wavenumbers.

The zonal wind amplitudes of the 10DWs deduced from the radiosonde observations at Santa Teresa $\left(-106.7^{\circ} \mathrm{W}, 31.9^{\circ} \mathrm{N}\right)$ and Perth Airport $\left(116.0^{\circ} \mathrm{E}, 31.9^{\circ} \mathrm{S}\right)$ are provided in the left panels of Figure 3 . Notable 10DWs appear in two layers (5-15 km and 25-32 km) at the mid-latitudes in the TLS in both hemispheres, which agrees well with the results from the Lomb-Scargle periodograms. Within the 5-15 km layer, strong wave activities appear in February $\left(14 \mathrm{~ms}^{-1}\right)$, March $\left(18 \mathrm{~ms}^{-1}\right)$, May $\left(14 \mathrm{~ms}^{-1}\right)$, September $\left(11 \mathrm{~ms}^{-1}\right)$, November $\left(13 \mathrm{~ms}^{-1}\right)$, and December $\left(12 \mathrm{~ms}^{-1}\right)$ in the $\mathrm{NH}$ and in January $\left(12 \mathrm{~ms}^{-1}\right)$, March $\left(12 \mathrm{~ms}^{-1}\right)$, April $\left(18 \mathrm{~ms}^{-1}\right)$, May $\left(19 \mathrm{~ms}^{-1}\right)$, June $\left(19 \mathrm{~ms}^{-1}\right)$, July $\left(16 \mathrm{~ms}^{-1}\right)$, August $\left(16 \mathrm{~ms}^{-1}\right)$, September $\left(14 \mathrm{~ms}^{-1}\right)$, October $\left(17 \mathrm{~ms}^{-1}\right)$, November $\left(11 \mathrm{~ms}^{-1}\right)$, and December $\left(11 \mathrm{~ms}^{-1}\right)$ in the $\mathrm{SH}$. The waves in the $\mathrm{NH}$ are notable in spring, autumn and winter but weak in summer, and the strongest wave activity occurs in spring. Compared to their counterparts in the $\mathrm{NH}$, the 10DWs in the $\mathrm{SH}$ have slightly stronger amplitudes and more seasonal coverage. In particular, significant wave activities are observed even in summer, while the strongest wave activities take place in autumn and winter. The wave activities at 10-13 km are accompanied by strong eastward jets (Figure1). Within the 25-32 km layer, strong 10DWs appear in January $\left(18 \mathrm{~ms}^{-1}\right)$, March $\left(18 \mathrm{~ms}^{-1}\right)$, and December $\left(10 \mathrm{~ms}^{-1}\right)$ in the $\mathrm{NH}$ and in May $\left(9 \mathrm{~ms}^{-1}\right)$, July $(7$ $\left.\mathrm{ms}^{-1}\right)$, and August $\left(9 \mathrm{~ms}^{-1}\right)$ in the SH. Hence, in this layer, mid-latitude 10DWs with notable amplitudes exist in the $\mathrm{NH}$ during winter and spring and in the SH during winter and autumn, and the 10DWs in the $\mathrm{NH}$ have a stronger amplitude than those in the $\mathrm{SH}$. 
For comparison, the zonal winds of the 10DWs deduced from the MERRA-2 data at the same grid nodes as mentioned above are also provided in the right panels of Figure 3 and display very similar spatial and temporal distributions to those deduced from the radiosonde observations. However, subtle differences are still present. In particular, the radiosonde-derived 10DWs above $25 \mathrm{~km}$ in the $\mathrm{NH}$ are more intensive than those from the MERRA-2 data in January and March.

\section{Dominant Modes Of The Mid-latitude 10dws In The Tls}

The 10DWs shown in the above section are the combination of multiple modes of 10DWs with different zonal wavenumbers. Some observational studies also confirmed these 10DWs in the troposphere of $\mathrm{NH}$ (Huang et al., 2009; Wang et al., 2012; Huang et al., 2017) but could not provide zonal wavenumber information because the applied observation data were from a single site. To reveal the dominant modes of those 10DWs, we use the MERRA-2 data along the same lines of latitude to calculate the frequencywavenumber spectra. The results in the above section demonstrate that the 10DWs are the strongest at $\sim 11 \mathrm{~km}$ in the troposphere and $\sim 31 \mathrm{~km}$ in the lower stratosphere, so we plot the frequency-wavenumber spectra at these two heights. To identify the prevailing modes of the 10DWs in 2020, a sliding 30-day window is adopted, this time with an increment of 10 days. Within each window, the time and zonal averages are removed from the raw data as the background component. Then, the frequencywavenumber spectra are calculated for the residuals, and 34 amplitude spectra are acquired throughout the whole year. Finally, we calculate and normalize their arithmetic average.

The normalized frequency-wavenumber spectra of the zonal wind disturbance at $\sim 11 \mathrm{~km}$ in 2020 are provided in the top row of Figure 4. The left panels show the results at $32^{\circ} \mathrm{N}$, while the right panels show the results at $32^{\circ} \mathrm{S}$. It should be noted that the horizontal axis, where positive zonal wavenumbers represent eastward propagation and negative zonal wavenumbers signify westward propagation. In the following, the westward-propagating and eastward-propagating modes with zonal wavenumber $\mathrm{n}$ are referred to as $\mathrm{Wn}$ and En, respectively, for simplicity. In the troposphere, the eastward-propagating modes are stronger than the westward-propagating modes. Among the eastward-propagating modes, those with larger wavenumbers are stronger than those with smaller wavenumbers. Furthermore, the eastwardpropagating modes in the $\mathrm{NH}$ are weaker than those in the $\mathrm{SH}$. In the $\mathrm{NH}, \mathrm{E} 3$ and $\mathrm{E} 6$ are almost as strong. In the SH, E5 is obviously stronger than the other modes. Likewise, the normalized frequencywavenumber spectra of the zonal wind disturbance at $\sim 31 \mathrm{~km}$ in 2020 are provided in the bottom row of Figure 4. The left panels show the results at $32^{\circ} \mathrm{N}$, while the right panels show the results at $32^{\circ} \mathrm{S}$. Only the modes with small wavenumbers, e.g., 1 and 2, exist in the lower stratosphere. The strongest mode in the $\mathrm{NH}$ is $\mathrm{W} 1$, while the strongest mode in the $\mathrm{SH}$ is $\mathrm{E} 2$.

The westward-propagating and eastward-propagating modes in the stratosphere and above with small wavenumbers, e.g., 1 and 2 were widely revealed by previous studies (Hirooka \& Hirota, 1985; Forbes \& Zhang, 2015; John \& Kumar, 2016; Huang et al., 2021). The dominant modes in the troposphere are the focus of our research. Figure 4 only provides average intensity of each mode at $~ 11$ km in 2020; as such

to reveal the temporal and spatial evolution characteristics of the eastward-propagating modes with large 
wavenumbers (E3-E6), the MERRA-2 data are harmonically fitted along the same lines of latitude using a sliding 30-day window with an increment of 1 day. Within each window, harmonic fits are performed on the residuals in the period range from 8.0 to 12.0 days in increments of 0.5 days. The formula used for the fitting is as follows:

$$
f^{\prime}(\lambda, t)=A \cos \left(\frac{2 \pi}{T} t-s \lambda-\theta\right)
$$

2

where $t, A, T$, and $\theta$ are the same quantities as in Eq. (1). In addition, $\lambda$ is the longitude in radians, and $s$ is the zonal wavenumber, where positive zonal wavenumbers represent eastward propagation and negative zonal wavenumbers signify westward propagation. For a certain mode of a 10-day wave, its amplitude at any given height in each window corresponds to the one fit among these periods that has the largest amplitude.

To ensure that the fitting result represents the actual signal rather than noise, we replace the zonal wind from the MERRA-2 data with values from a randomly generated Gaussian distribution with zero mean and a standard deviation associated with the values deduced from the MERRA-2 data. Then, the same method is utilized to fit the random data, and the largest amplitude values of the fitted waves are used to estimate the worst-case noise levels (McDonald et al., 2011). The largest worst-case noise level among $\mathrm{E} 3, \mathrm{E} 4, \mathrm{E} 5$ and $\mathrm{E} 610 \mathrm{DW}$ at $32^{\circ} \mathrm{N}$ and $32^{\circ} \mathrm{S}$ is $\sim 1 \mathrm{~ms}^{-1}$.

Classic PW studies indicate that the atmospheric background state affects planetary-scale wave propagation by altering the refractive index (Charney \& Drazin, 1961); hence, the planetary-scale wave amplitude and phase strongly depend on the background wind conditions. Therefore, we whether these eastward-propagating modes with large wavenumbers propagate freely in the atmospheric background by calculating the refractive index. The formula is as follows (Andrews et al., 1987):

$$
n^{2}=\frac{q_{y}}{\mathbb{u}-c}-\frac{f^{2}}{4 H^{2} N^{2}}-\frac{s^{2}}{a^{2} \cos ^{2} \varphi}
$$

3

where the parameter $N$ refers to the buoyancy frequency, $u$ is the zonal-mean zonal wind, $\varphi$ is the latitude in radians, $a$ is the mean Earth radius, $f$ is the Coriolis parameter $\left(f=2 \Omega \sin \varphi ; \Omega=7.292 \times 10^{-5} \mathrm{rad}^{-1}\right), H$ is the scale height, $s$ is the zonal wavenumber, $c$ is the phase velocity, and $\overline{q_{y}}$ is the basic northward potential vorticity gradient, which can be written as follows (Andrews et al., 1987):

$$
q_{y}=\beta-\varpi_{y y}-\frac{f^{2}}{\rho_{0}}\left(\frac{\rho_{0}}{N^{2}} \rrbracket_{Z}\right)_{Z}
$$


In the above formulas, the overbars denote zonal averages, while the subscripts denote partial derivatives. The parameter $\beta$ is the Rossby parameter $(\beta=2 \Omega \sin \varphi / a ; a, \varphi$ and $\Omega$ are the same quantities as those in Eq. (3)), and $\rho_{0}$ is the basic state density. We obtain all parameters from the MERRA-2 data.

Refractive index squared diagnoses the influence of the zonal mean flow on planetary-scale wave propagation in the meridional and vertical plane. The wave propagates meridionally and/or vertically in the regions where $n^{2}>0$ but are evanescent or reflected in the regions where $n^{2}<0$. Negative values of $n^{2}$ (indicating regions of evanescence) are shaded in red.

Figure 5 shows time-altitude contours of zonal wind amplitudes for E3, E4, E5 and E6 $10 \mathrm{DW}$ at $32^{\circ} \mathrm{N}$ in 2020. The time variations of these four waves show both similarities and differences. They are all strong in the spring and winter, and weak or even indiscernible in the summer and autumn, which is consistent with the seasonal variation of the subtropical jet (top row of Figure 1). This indicates that these wave activities and the eastward jets might be positively correlated. However, the strongest activities of these four waves occurs in different months, and their magnitudes is also somewhat different. The largest amplitudes of the E3, E4, E5, and E6 10DWs are respectively about 5.6, 5.5, 6.2, and $5.4 \mathrm{~ms}^{-1}$, which occur in November, February, March, and January respectively.

Likewise, the time-altitude contours of zonal wind amplitudes for E3, E4, E5 and E6 10DW at $32^{\circ} \mathrm{N}$ in 2020 are provided in Figure 6 . Just like those in the $\mathrm{NH}$, the time variations of these four waves display some similar and different characteristics. They are all no negligible throughout the year, and the amplitudes in spring, autumn and winter are greater than those in summer, which agrees well with the seasonal variation of the subtropical jet in the $\mathrm{SH}$ (bottom row of Figure1). This also implies a positive correlation between the wave activities and the eastward jet. E5 is obviously the strongest mode, and E4 is stronger than E3 and E6. Similar to the situation in the $\mathrm{NH}$, the strongest activities of these four waves in the SH occurs in different months. The largest E3, E4, E5, and E6 10DW amplitudes in zonal wind are respectively about 4.9, 8.2, 10.5, and $5.6 \mathrm{~ms}^{-1}$, which appear in September, June, May, and July respectively.

We highlight the evanescence regions, where wave propagation is prohibited, with red shadow in these two figures. The wave amplitude is large in the freely propagating region, while small in the evanescence region, obviously. In both hemispheres, there are very thick evanescence regions above the freely propagating regions at $\sim 15 \mathrm{~km}$, which prevent these waves from propagating upward across the tropopause; as such these eastward-propagating modes with large wavenumbers are weak or even disappear in the stratosphere and above. Since the background zonal wind within the whole display height range $(0-32 \mathrm{~km})$ at $32^{\circ} \mathrm{N}$ from July to August is westward or weakly eastward, there is no freely propagating region.

The above result implies a positive correlation between the wave activities and the eastward jet. Then the correlation coefficients between the amplitudes of E3, E4, E5 and E6 10DWs and the zonal-mean zonal wind at $\sim 11 \mathrm{~km}$ in 2020 is calculated. Figure 7 and Figure 8 show the zonal wind amplitudes of the 
eastward-propagating 10DWs with zonal wavenumbers from 3 to 6 at $\sim 11 \mathrm{~km}$ deduced from MERRA-2 data at $32^{\circ} \mathrm{N}$ and $32^{\circ} \mathrm{S}$, respectively. Yellow line marks the zonal-mean zonal wind. For a better representation, the zonal-mean zonal wind is scaled by 7. In both hemisphere, the seasonal variations of $\mathrm{E} 3, \mathrm{E} 4, \mathrm{E} 5$ and E6 10DWs are consistent with those of the zonal-mean zonal wind. The correlation coefficients between the E3/E4/E5/E6 10DW and the zonal-mean zonal wind are 0.57/0.68/0.71/0.67 in the $\mathrm{NH}$, while $0.31 / 0.64 / 0.09 / 0.17$ in the SH. All the coefficients except the one for the E5 10DW in the SH are far greater than the value corresponding to the $99 \%$ confidence level of a test of statistical significance, which implying strong and positive correlations. The coefficient for the E5 10DW also signifies a positive correlation, but not as strong as the others. We speculate that there are other reasons for the time variation of the E5 10DW in addition to the background zonal wind.

\section{Case Study Of The Most Dominant Mode In The Sh}

Figure 7 and Figure 8 show that in the troposphere, the predominant 10DW mode in the SH, i.e., E5, is much stronger than the predominant 10DW mode in the $\mathrm{NH}$. And, its correlation with the background zonal wind indicates a complex time variation mechanism. Therefore, we further investigate the E5 10DW in the following. The results in the Figure 8 show that the E5 10DW was strongest on May 12, 2020, at $\sim 11 \mathrm{~km}$ in the SH. To confirm that this phenomenon was an enhanced event rather than a climatological variation, the amplitudes of the E5 10DW at $32^{\circ} \mathrm{S}$ and $\sim 11 \mathrm{~km}$ on May 12 in each year from 2006 to 2020 are obtained using the abovementioned fitting method, and the arithmetic average of these 15 amplitudes is taken as the climatological mean amplitude. We then ascertain whether the strength of the E5 10DW was due to a climatological variation or an enhanced event by comparing the climatological mean amplitudes plus twice the standard deviation with the amplitudes in 2020 . The results of the significance test are presented in Figure 9, which demonstrates that the E5 10DW amplitude on May 12, 2020 , is significantly different from the climatology at the $95 \%$ confidence level because the amplitude in 2020 is larger than the climatological mean amplitude plus twice the standard deviation (red line).

Therefore, we postulate that the amplification of the E5 10DW on May 12,2020, represents an enhanced event instead of climatological variation.

Because the amplification of wave amplitudes is a dynamic process, we choose several dates at equal intervals to analyze the amplitude trend. Accordingly, the refractive index squared and the Eliassen-Palm (EP) flux and its divergence on April 24, April 30 and May 6 are examined to explain the latitude-height structures and investigate the local excitation and dissipation processes.

The EP flux and its divergence are analyzed by using the zonal transformed Eulerian mean momentum equation under the quasi-geostrophic approximation in spherical log (pressure) coordinates (Edmon et al. 1980; Andrew et al. 1987; Andrew 1987) by applying the formula below:

$$
\mathfrak{u}_{t}+\mathbb{V}^{*}\left[(\operatorname{acos} \varphi)^{-1}(u \cos \varphi)_{\varphi}-f_{0}\right]+\mathbb{w}^{*} \mathfrak{u}_{z}=\left(\rho_{0} \operatorname{acos} \varphi\right)^{-1} \nabla \cdot F
$$


The vector $\mathbf{F}$ is known as the EP flux, of which the meridional and vertical components are defined, respectively, as follows:

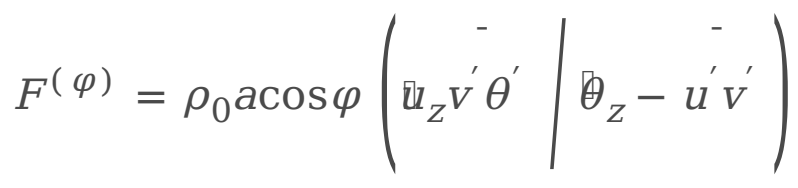

5

and

$$
F^{(z)}=\rho_{0} \operatorname{acos} \varphi\left\{\left[f_{0}-(\operatorname{acos} \varphi)^{-1}(u \cos \varphi)_{\varphi}\right] v^{\prime} \theta^{\prime} \mid \oplus_{z}-u^{\prime} w^{\prime}\right\}
$$

6

where the prime symbol denotes a perturbation quantity (deviation from the zonal average); $\mathbb{V}^{*}$ and $\mathbb{w}^{*}$ are the meridional and vertical components, respectively, of the residual mean meridional circulation; $u, v$, and $w$ are the zonal, meridional and vertical winds, respectively; and $\theta$ is the potential temperature. We obtain $u, \nabla$, and $\rho_{0}$ from the MERRA-2 data, based on which $u^{\prime}, v^{\prime}$ and $\theta^{\prime}$ are obtained using the same fitting method mentioned above. Since the term proportional to $v^{\prime} \theta^{\prime} \mid \bigoplus_{Z}$ dominates the vertical EP flux component, the term proportional to $u^{\prime} w^{\prime}$ is omitted from the calculations. In addition, the meridional and vertical components of the EP flux refer to a generalization of the group velocity concept so that their cross-sections can be used to visualize the flow of the wave energy density (Edmon et al. 1980; Andrews 1987; Chen et al., 2005). Because of the density factors in Eqs. (5) and (6), the components of the EP flux have a large dynamic range. For a better height representation, the meridional and vertical components of the EP flux are scaled by the density, namely, $F^{(\varphi)} / \rho_{0}$ and $F^{(z)} / \rho_{0}$ (Huang et al., 2021), which we refer to as EPY and EPZ, respectively, and display them as red vectors in the right panels in Figure 10. The zonal force per unit mass acting on the mean state is defined as $D F=\left(\rho_{0} a \cos \varphi\right)^{-1} \nabla \cdot F$, which is shown with color contours in the right panels in Figure 10. Regions of positive (negative) EP flux divergence are sources (sinks) of wave energy, where the wave is amplified (dissipated).

Figure 10 plots the refractive index squared, EP flux and its divergence on April 24 (top row), April 30 (middle row) and May 6 (bottom row). The red vectors of the EP flux in the right panels of Figure 10 indicate that the amplification of the E5 10DW at $32^{\circ} \mathrm{S}$ and $\sim 11 \mathrm{~km}$ is the result of the transmission of two wave energy flows. One flow starts at $32-40^{\circ} \mathrm{S}$ and $3-4 \mathrm{~km}$ and propagates upward and then toward the equator, which we call an extratropical surface source. The other flow starts from 39-49 ${ }^{\circ} \mathrm{S}$ and 8-12 $\mathrm{km}$ and propagates almost horizontally toward the equator. On April 24, the region at $49^{\circ} \mathrm{S}$ and $10 \mathrm{~km}$ is a 
source of the E5 10DW, as the EP flux divergence is indeed large and positive here with a maximum of $11.9 \mathrm{~ms}^{-1}$ day $^{-1}$; the horizontal energy flow originates from this region. On April 30, this source region moves to $47^{\circ} \mathrm{S}$ and $10 \mathrm{~km}$, where the EP flux divergence also shows large positive values with a maximum of $7.1 \mathrm{~ms}^{-1} \mathrm{day}^{-1}$. On May 6 , the source at $10 \mathrm{~km}$ shifts to $39^{\circ} \mathrm{S}$ with a maximum divergence of $7.9 \mathrm{~ms}^{-1}$ day $^{-1}$. Otherwise, the zonal wind amplitudes of the E5 10DW in the left panel of Figure 9 show a bimodal structure in the latitude-altitude section. In addition to the abovementioned extratropic surface source, the sources at $49^{\circ} \mathrm{S}$ and $10 \mathrm{~km}$ on April 24 and at $47^{\circ} \mathrm{S}$ and $10 \mathrm{~km}$ on April 30 can explain the formation of the peak at $51^{\circ} \mathrm{S}$ and $\sim 11 \mathrm{~km}$. In addition, the region where $n^{2}<0$ in the left panels and the red vectors of the EP flux in the right panels of Figure 9 both indicate that the energy flow of E5 10DW cannot propagate upward from the tropospheric jet height to the stratosphere or across the equator into the $\mathrm{NH}$.

\section{Summary And Conclusions}

Using radiosonde observations and MERRA-2 data, the characteristics of the mid-latitude 10DWs in the TLS of both the $\mathrm{NH}$ and the $\mathrm{SH}$ in 2020 are simultaneously studied. The main results and conclusions are as follows:

1. Single-site radiosonde observations in both hemispheres show that 10DWs exist in mid-latitudes in the TLS. In the troposphere of both hemispheres, strong 10DW activities are always accompanied by strong eastward jets (10-13 km) implying that the 10DW activities are related to eastward jets; this also implies that the 10DWs in the $\mathrm{NH}$ and $\mathrm{SH}$ might have a similar formation mechanism. In the lower stratosphere, 10DWs appear in boreal winter and spring as well as austral winter and autumn. It should be noted that the 10DWs observed at a single site are the combination of multiple modes of the 10DWs with different zonal wavenumbers, the magnitude of which is greater than that of a single mode.

2. MERRA-2 data along latitude $32^{\circ} \mathrm{N}$ and $32^{\circ} \mathrm{S}$ show that the $10 \mathrm{DW}$ field in the troposphere is very different from the situation in the lower stratosphere. In the troposphere, the eastward-propagating 10DW modes are stronger than the westward-propagating modes, which agrees well with previous work (Huang et al. 2017). Moreover, among the eastward-propagating modes, those with larger wavenumbers, i.e., E3, E4, E5 and E6 are stronger than those with smaller wavenumbers, i.e., E1 and E2. As such, the eastwardpropagating modes with larger wavenumbers dominant the 10DW field in the troposphere. While in the lower stratosphere, the 10DW field is dominated by modes with small zonal wavenumbers, i.e., W1, W2, E1 and E2, which is consistent with the previous studies (Huang et al. 2021).

3. Further analyses on E3, E4, E5 and E6 modes in the troposphere of both hemispheres shows that these four modes are positively correlated to the background zonal wind. The calculated refractive index squared reveals the control of background wind on these waves. For these four modes, weak eastward jets can cause negative refractive index squared; as such these four modes activities are always accompanied by strong eastward jets. In addition, there are thick evanescence regions above the freely 
propagating regions at $\sim 15 \mathrm{~km}$, which prevent these waves from propagating upward across the tropopause; as such these waves are not found in the stratosphere and above.

4. The temporal evolution characteristics of the 10DW modes reveal dramatic E5 10DW activity on May 12,2020 , at $32^{\circ} \mathrm{S}$ and $\sim 11 \mathrm{~km}$. Then, a detailed case study of this E5 10DW activity indicates that is the most intense in the past 14 years and can be regarded as an enhanced event rather than a climatological variation. The refractive index squared and the EP flux and its divergence on three dates before the central date, i.e., April 24, April 30 and May 6, are further examined to explain the latitude-height structures and investigate the local excitation and dissipation processes. From this case study, we summarize two key conclusions. First, there are two sources of the E5 10DW: one source originates from the extratropical surface at mid-latitudes and shows first upward and then equatorward/poleward movement; the other source is located at $39-49^{\circ} \mathrm{S}$ and $8-12 \mathrm{~km}$, and its energy flows horizontally to the equator/poles, leading to the formation of a bimodal structure in the latitude-altitude section. We note that the EP flux and its divergence reflect only the source and energy flow of waves, whereas the generation mechanism remains unclear. Second, the energy flow of E5 10DW cannot propagate upward across the tropopause and equatorward across the equator. Since there is a thick region of evanescence around the equator, the E5 10DW generated in one hemisphere does not affect the atmosphere in the other hemisphere.

\section{Abbreviations}

PWs: Planetary waves; 10DWs: 10-day waves; NH: Northern Hemisphere; SH: Southern Hemisphere; MERRA-2: Modern Era Retrospective-Analysis for Research and Applications version 2; TLS: Troposphere and lower stratosphere; EP: Eliassen-Palm.

\section{Declarations}

\section{Acknowledgments}

We are grateful to the NOAA and the University of Wyoming for providing the high-resolution radiosonde data used in this study. We also sincerely thank the Goddard Earth Sciences Data and Information Services Center (GES DISC) for the dissemination of the MERRA-2 data.

\section{Authors' contributions}

LY conceived and coordinated this study, and wrote the first draft of the paper. $\mathrm{CH}$ and SZ performed analyses related to the present study, and interpreted the results. $\mathrm{KH}, \mathrm{YG}$ and $\mathrm{MZ}$ contributed to the scientific interpretation. JZ carried out the high-resolution radiosonde data processing. All authors read and approved the final manuscript.

\section{Funding}


The present work is jointly supported by the National Natural Science Foundation of China (grant nos. 41874178, 42074182 and 4212780004).

\section{Availability of data and materials}

The high-resolution radiosonde data used and analyzed in the present study are available from https://www.sparc-climate.org/data-centre/data-access/us-radiosonde/ and http://weather.uwyo.edu. The MERRA-2 data used and analyzed in the present study are available from https://disc.gsfc.nasa.gov.

\section{Competing interests}

The authors declare that they have no competing interests.

\section{Author details}

${ }^{1}$ School of Electronic Information, Wuhan University, Wuhan, China

${ }^{2}$ Key Laboratory of Geospace Environment and Geodesy, Ministry of Education, Wuhan, China

${ }^{3}$ State Key Laboratory of Information Engineering in Surveying, Mapping and Remote Sensing, Wuhan University, Wuhan, China

${ }^{4}$ Hubei Subsurface Multi-Scale Imaging Key Laboratory, Institute of Geophysics and Geomatics, China University of Geosciences, Wuhan, China

\section{References}

1. Ahlquist JE (1982) Normal-Mode Global Rossby Waves: Theory and Observations. J Atmos Sci 39(2):193-202. https://doi.org/10.1175/1520-0469(1982)039<0193:NMGRWT>2.0.C0;2

2. Alexander MJ, Geller M, McLandress C, Polavarapu S, Preusse P, Sassi F, Sato K, Eckermann S, Ern M, Hertzog A, Kawatani Y, Pulido M, Shaw TA, Sigmond M, Vincent R, Watanabe S (2010) Recent developments in gravity-wave efects in climate models and the global distribution of gravity-wave momentum fux from observations and models. Q J R Meteorol Soc 136:1103-1124. https://doi.org/10.1002/qj.637

3. Andrews DG (1987) On the interpretation of the Eliassen-Palm flux divergence. Q J R Meteorol Soc 113(475):323-338. https://doi.org/10.1002/qj.49711347518

4. Charney JG, Drazin PG (1961) Propagation of Planetary-Scale Disturbances from the Lower into the Upper Atmosphere. J Geophys Res 66(1):83-109. https://doi.org/10.1029/JZ066i001p00083 
5. Chen S, Meek CE, Manson AH, Chshyyolkova T (2011) The 10-day planetary wave examined by Odin/OSIRIS ozone profiles during late March 2002: Comparison with UKMO and MF radar data. Int J Remote Sens 32(6):153-544. https://doi.org/10.1080/01431160903571817

6. Chen W, Yang S, Huang R-H (2005) Relationship between stationary planetary wave activity and the East Asian winter monsoon. J Geophys Res Atmos 110:D14110. https://doi.org/10.1029/2004JD005669

7. Edmon HJ, Hoskins BJ, McIntyre ME (1980) Eliassen-Palm cross sections for the troposphere. J Atmos Sci 37(12):2600-2616. https://doi.org/10.1175/1520-0469(1980)037<2600:EPCSFT>2.0.C0;2

8. Fagundes PR, Pillat VG, Bolzan MJA, Sahai Y, Becker-Guedes F, Abalde JR, Aranha SL, Bittencourt JA (2005) Observations of $\mathrm{F}$ layer electron density profiles modulated by planetary wave type oscillations in the equatorial ionospheric anomaly region. J Geophys Res Space Physics 110:A12302. https://doi.org/10.1029/2005JA011115

9. Forbes JM, Garrett HB (1979) Theoretical studies of atmospheric tides. Rev Geophys 17(8):19511981. https://doi.org/10.1029/rg017i008p01951

10. Forbes JM, Zhang X (2015) Quasi-10-day wave in the atmosphere. J Geophys Res Atmos 120(21):11079-11089. https://doi.org/10.1002/2015JD023327

11. Fritts DC, Alexander MJ (2003) Gravity wave dynamics and effects in the middle atmosphere. Rev Geophys 41(1):1003. https://doi.org/10.1029/2001rg000106

12. Gelaro R, McCarty W, Suarez MJ, Todling R, Molod A, Takacs L et al. (2017) The Modern-Era Retrospective Analysis for Research and Applications, version 2 (MERRA-2). J Climate 30(14):54195454. https://doi.org/10.1175/JCLI-D-16-0758.1

13. Guo J, Zhang J, Yang K, Liao H, Zhang S, Huang K et al (2021) Investigation of Near-Global Daytime Boundary Layer Height Using High-Resolution Radiosondes: First Results and Comparison with ERA5, MERRA-2, JRA-55, and NCEP-2 Reanalyses. Atmos Chem Phys 21:17079-17097. https://doi.org/10.5194/acp-21-17079-2021

14. Gong Y, Wang H, Ma Z, Zhang S, Zhou Q, Huang C, Huang K (2019) A statistical analysis of the propagating quasi 16-day waves at high latitudes and their response to sudden stratospheric warmings from 2005 to 2018. J Geophys Res Atmos 124(23):12617-12630. https://doi.org/10.1029/2019JD031482

15. Huang C, Zhang S, Yi F (2009) Intensive radiosonde observations of the diurnal tide and planetary waves in the lower atmosphere over Yichang $\left(111^{\circ} 18^{\prime} \mathrm{E}, 30^{\circ} 42^{\prime} \mathrm{N}\right)$, China. Ann Geophys $27(3): 1079-$ 1095. https://doi.org/10.5194/angeo-27-1079-2009

16. Huang C, Zhang S, Chen G, Zhang S, Huang K (2017) Planetary wave characteristics in the lower atmosphere over Xianghe $\left(117.00^{\circ} \mathrm{E}, 39.77^{\circ} \mathrm{N}\right)$, China, revealed by the Beijing MST radar and MERRA data. J Geophys Res Atmos 122(18):9745-9758. https://doi.org/10.1002/2017JD027029

17. Huang C, Li W, Zhang S, Chen G, Huang K, Gong Y (2021) Investigation of dominant traveling 10-day wave components using long-term MERRA-2 database. Earth Planets Space 73:85. https://doi.org/10.1186/s40623-021-01410-7 
18. Hirooka T, Hirota I (1985) Normal mode Rossby waves observed in the upper stratosphere. Part II: Second antisymmetric and symmetric modes of zonal wavenumbers 1 and 2. J Atmos Sci 42(6):536-548. https://doi.org/10.1175/1520-0469(1985)042<0536:NMRWOI>2.0.C0;2

19. Hirooka T (1986) Influence of normal mode Rossby waves on the mean field: Influence with quasistationary waves. J Atmos Sci 43(19):2088-2097. https://doi.org/10.1175/15200469(1986)043<2088:IONMRW>2.0.CO;2

20. He MS, Chau JL, Forbes JM, Thorsen D, Li GZ, Siddiqui TA et al (2020) Quasi-10-day wave and semidiurnal tide nonlinear interactions during the Southern Hemispheric SSW 2019 observed in the Northern Hemispheric Mesosphere. Geophys Res Lett 47(23):1029. https://doi.org/10.1029/2020gl091453

21. Irving D, Simmonds I (2015) A novel approach to diagnosing Southern Hemisphere planetary wave activity and its influence on regional climate variability, J Climate 28(23):9041-9057. https://doi.org/10.1175/JCLI-D-15-0287.1

22. John SR, Kumar KK (2016) Global normal mode planetary wave activity: A study using TIMED/SABER observations from the stratosphere to the mesosphere-lower thermosphere. Clim Dyn 47:3863-3881. https://doi.org/10.1007/s00382-016-3046-2

23. Kuroda Y, Chiba M, Shibata K, Yamazaki K (1994) Interference of the diurnal tide and normal-mode Rossby waves in the summer stratosphere, J Meteorol Soc Jpn 72(4):555-567. https://doi.org/10.2151/jmsj1965.72.4_555

24. Laštovička J (1996) Similarities in the variability of the lower ionosphere and foF2 in the period range of 2-15 days. Adv Space Res 18(3):117-120. https://doi.org/10.1016/0273-1177(95)00849-A

25. Lieberman RS, Hays PB (1994) An estimate of the momentum deposition in the lower thermosphere by the observed diurnal tide. J Atmos Sci 51(2):3094-3105. https://doi.org/10.1175/15200469(1994)051<3094:AEOTMD>2.0.CO;2

26. Luo Y, Manson AH, Meek CE, Igarashi K, Jacobi Ch (2001) Extra long period (20-40 day) oscillations in the mesosphere and lower thermospheric winds: Observations in Canada, Europe and Japan, and considerations of possible solar influences. J Atmos and Solar-Terr Phys 63(9):835-852. https://doi.org/10.1016/S1364-6826(00)00206-6

27. Luo J, Gong Y, Ma Z, Zhang S, Zhou Q, Huang C et al (2021) Study of the quasi 10-day waves in the MLT region during the 2018 February SSW by a meteor radar chain. J Geophys Res Space Physics 126(3):e2020JA028367. https://doi.org/10.1029/2020JA028367

28. McDonald AJ, Hibbins RE, Jarvis MJ (2011) Properties of the quasi 16 day wave derived from EOS MLS observations. J Geophys Res 116(D6):D06112. https://doi.org/10.1029/2010JD014719

29. Palo SE, Forbes JM, Zhang X, Russell JM, Mertens CJ, Mlynczak MG et al (2005) Planetary wave coupling from the stratosphere to the thermosphere during the 2002 Southern Hemisphere prestratwarm period. Geophys Res Lett 32(23):L23809. https://doi.org/10.1029/2005GL024298

30. Pancheva D, Mitchell NJ, Manson AH, Meek CE, Jacobi C, Portnyagin Y et al (2004) Variability of the quasi-2-daywave observed in the MLT region during the PSMOS campaign of June-August 1999. J 
Atmos and Solar-Terr Phys 66(6-9):539-565. https://doi.org/10.1016/j.jastp.2004.01.008

31. Pancheva D, Mukhtarov P, Mitchell NJ, Merzlyakov E, Smith AK, Andonov B et al (2008) Planetary waves in coupling the stratosphere and mesosphere during the major stratospheric warming in 2003/2004. J Geophys Res Atmos 113:D12105. https:// doi.org/10.1029/2007jd009011

32. Pendlebury D, Shepherd TG, Pritchard M, McLandress C (2008) Normal mode Rossby waves and their effects on chemical composition in the late summer stratosphere. Atmos Chem Phys 8(7):19251935. https://doi.org/10.5194/acp-8-1925-2008

33. Salby ML (1984) Survey of planetary-scale traveling waves: The state of theory and observations. Rev Geophys 22(2):209-236. https://doi.org/10.1029/rg022i002p00209

34. Salby ML, Callaghan PF (2001) Seasonal amplification of the 2-day wave: Relationship between normal mode and instability. J Atmos Sci 58(14):1858-1869. https://doi.org/10.1175/15200469(2001)058<1858:Saotdw>2.0.Co;2

35. Scargle JD (1982) Studies in astronomical time series analysis, II-Statistical aspects of spectral analysis of unevenly spaced data. Astrophys. J 263:835-853. https://doi.org/10.1086/160554

36. Wang JC, Palo SE, Forbes JM, Marino J, Moffat-Griffın T, Mitchell NJ (2021) Unusual quasi 10-day planetary wave activity and the ionospheric response during the 2019 Southern Hemisphere sudden stratospheric warming. J Geophys Res Space

Physics 126(6):e2021JA029286. https://doi.org/10.1029/2021JA029286

37. Wang R, Zhang SD, Yang HG, Huang KM. (2012). Characteristics of mid-latitude planetary waves in the lower atmosphere derived from radiosonde data. Ann Geophys 30(10):1463-

1477. https://doi.org/10.5194/angeo-30-1463-2012

38. Wang R, Zhang SD, Yi F (2010) Radiosonde observations of high-latitude planetary waves in the lower atmosphere. Sci China-Earth Sci 53:919-932. https://doi.org/10.1007/s11430-010-0069-0

39. Wu DL, Hays PB, Skinner WR (1994) Observations of the 5-day wave in the mesosphere and lower thermosphere. Geophys Res Lett 21(24):2733-2736. https://doi.org/10.1029/94GL02660

40. Yamazaki Y, Matthias V (2019) Large-amplitude quasi-10-day waves in the middle atmosphere during final warmings. J Geophys Res Atmos 124(17-18):9874-

9892. https://doi.org/10.1029/2019JD030634

41. Yu FR, Huang KM, Zhang SD, Huang CM, Yi F, Gong Y et al (2019) Quasi 10- and 16-day wave activities observed through meteor radar and MST radar during stratospheric final warming in 2015 spring. J Geophys Res Atmos 124(12):6040-6056. https://doi.org/10.1029/2019JD030630

42. Zhang SD, Yi F, Huang CM, Chen ZY (2008) Intensive radiosonde observations of gravity waves in the lower atmosphere over Yichang (111 $\left.18^{\prime} \mathrm{E}, 30^{\circ} 42^{\prime} \mathrm{N}\right)$, China. Ann Geophys 26(7):2005-2018. https://doi.org/10.5194/angeo-26-2005-2008

\section{Figures}




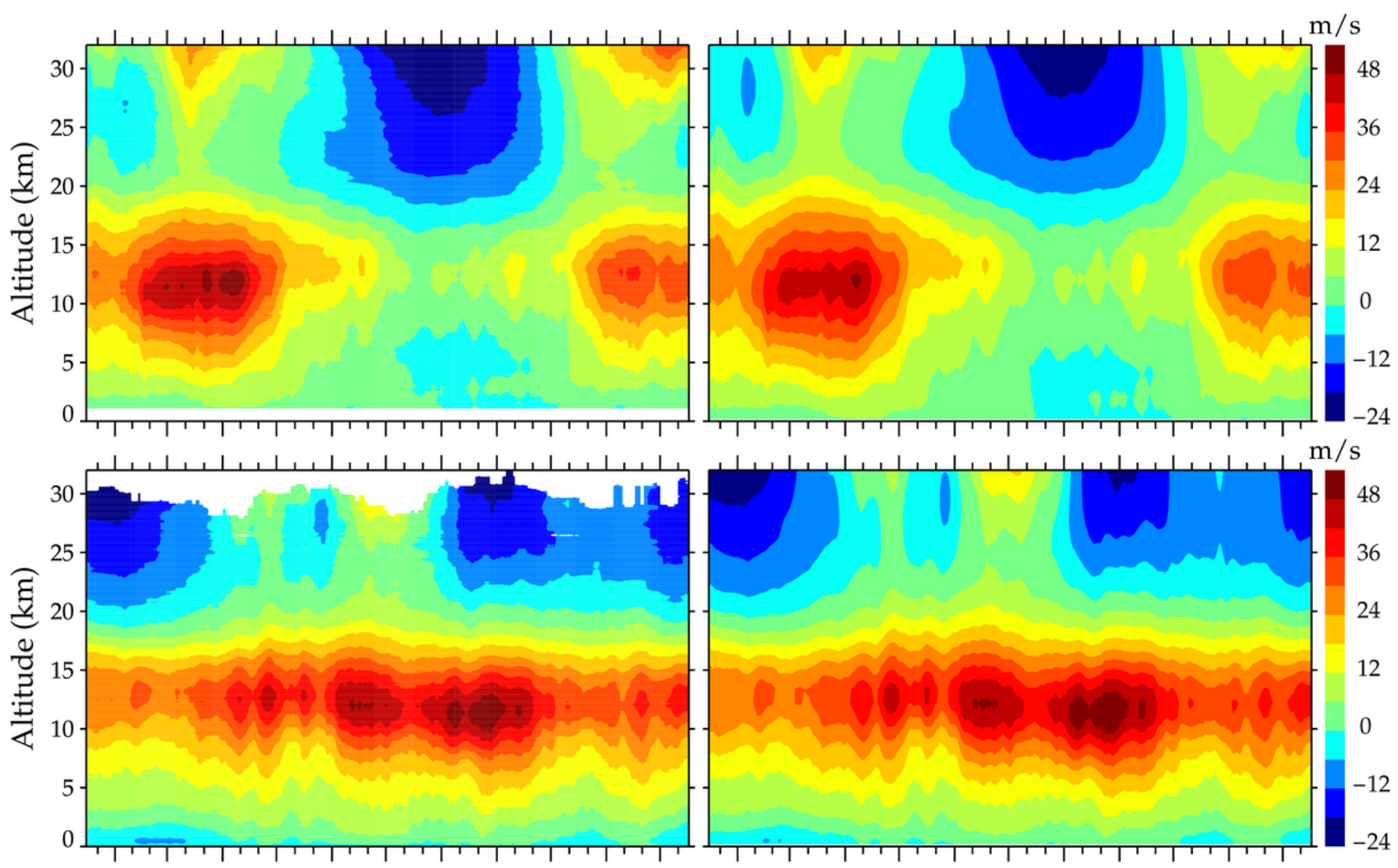

Feb. Mar. Apr. May Jun. Jul. Aug. Sept. Oct. Nov. Dec. Feb. Mar. Apr. May Jun. Jul. Aug. Sept. Oct. Nov. Dec. Month Month

\section{Figure 1}

Background zonal winds at Santa Teresa (top row) and Perth Airport (bottom row) deduced from the radiosonde observations (left panels) and MERRA-2 data (right panels) in 2020. 

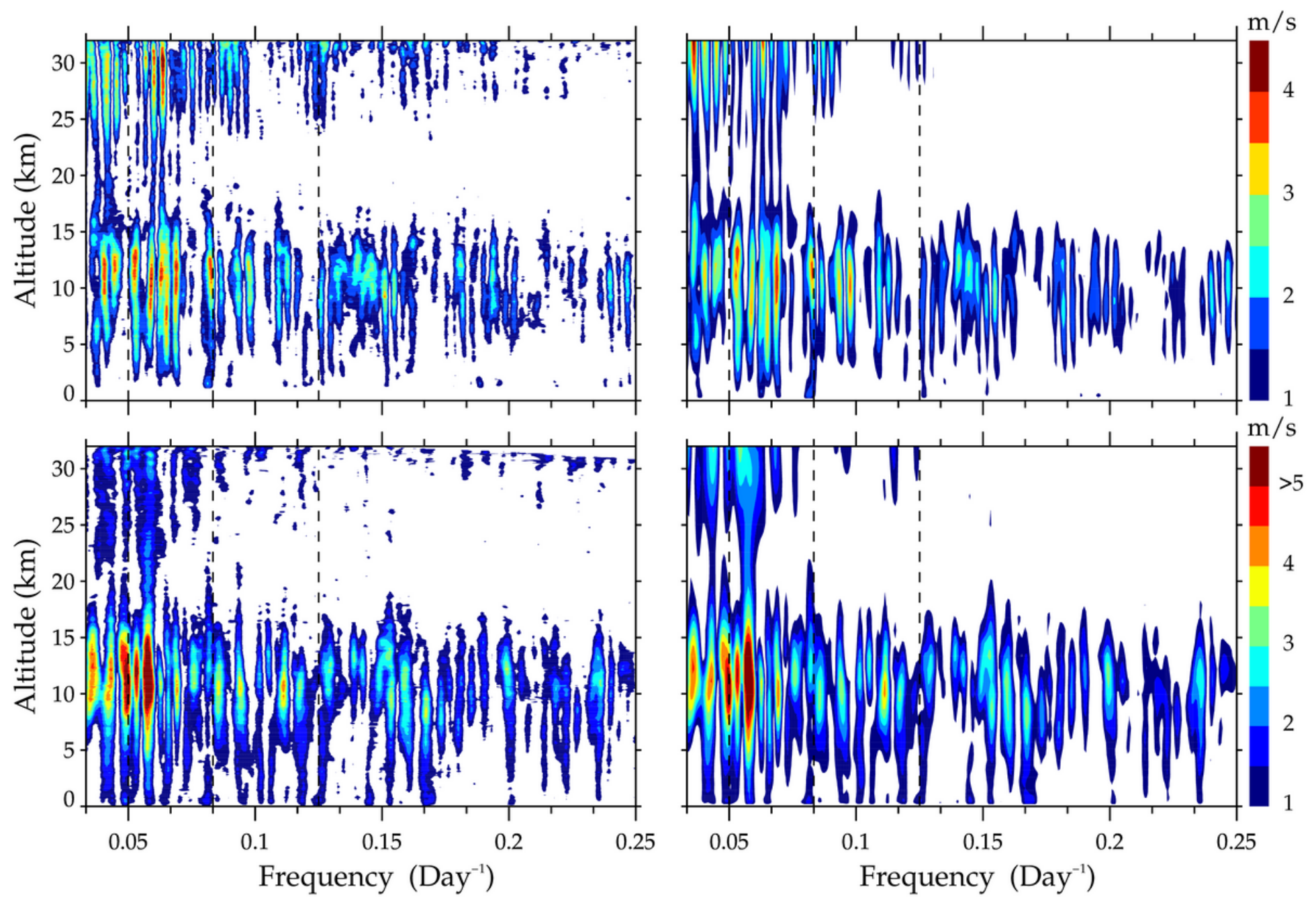

Figure 2

Lomb-Scargle periodograms of the zonal winds at Santa Teresa (top row) and Perth Airport (bottom row) deduced from the radiosonde observations (left panels) and MERRA-2 data (right panels) in 2020. The three dashed vertical lines denote three periods of 20,12 , and 8 days. 


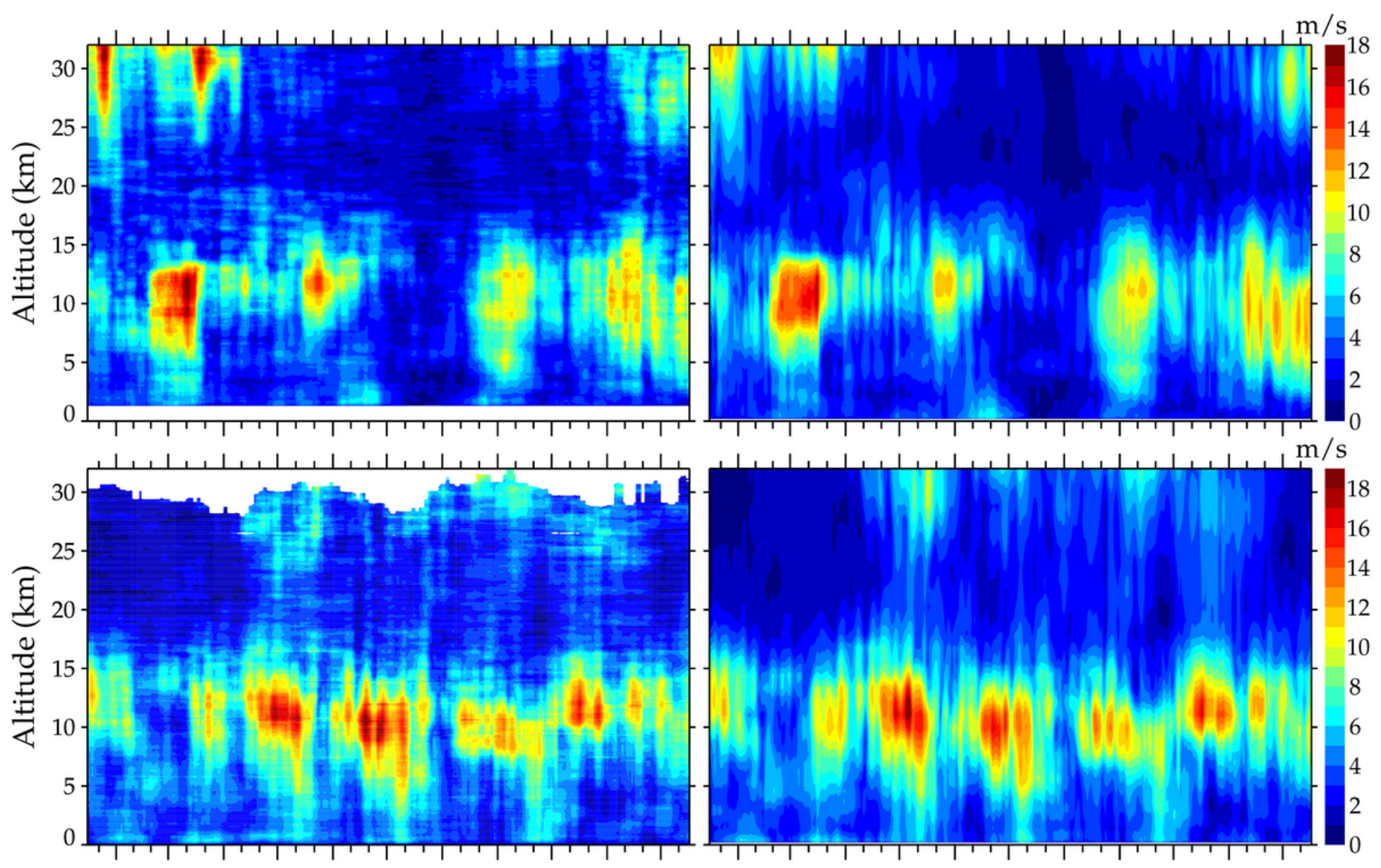

Feb. Mar. Apr. May Jun. Jul. Aug. Sept. Oct. Nov. Dec. Feb. Mar. Apr. May Jun. Jul. Aug. Sept. Oct. Nov. Dec. Month Month

\section{Figure 3}

Zonal wind amplitudes of the 10DWs at Santa Teresa (top row) and Perth Airport (bottom row) deduced from the radiosonde observations (left panels) and MERRA-2 data (right panels) in 2020. 

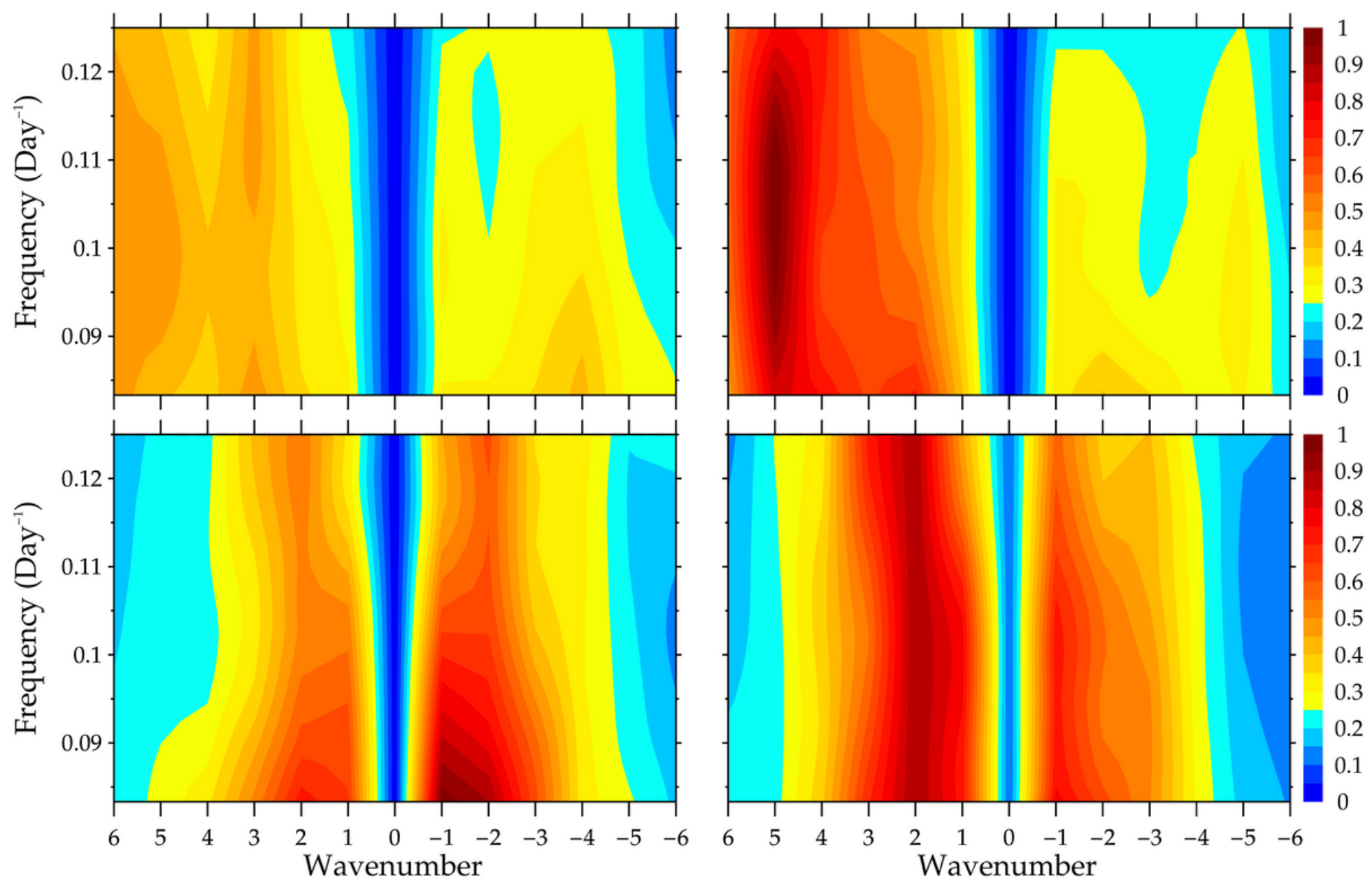

Figure 4

Normalized frequency-wavenumber spectra of the zonal wind disturbances at $\sim 11 \mathrm{~km}$ (top row) and $~ 31$ $\mathrm{km}$ (bottom row) along latitudes of $32^{\circ} \mathrm{N}$ (left panels) and $32^{\circ} \mathrm{S}$ (right panels) in 2020. 

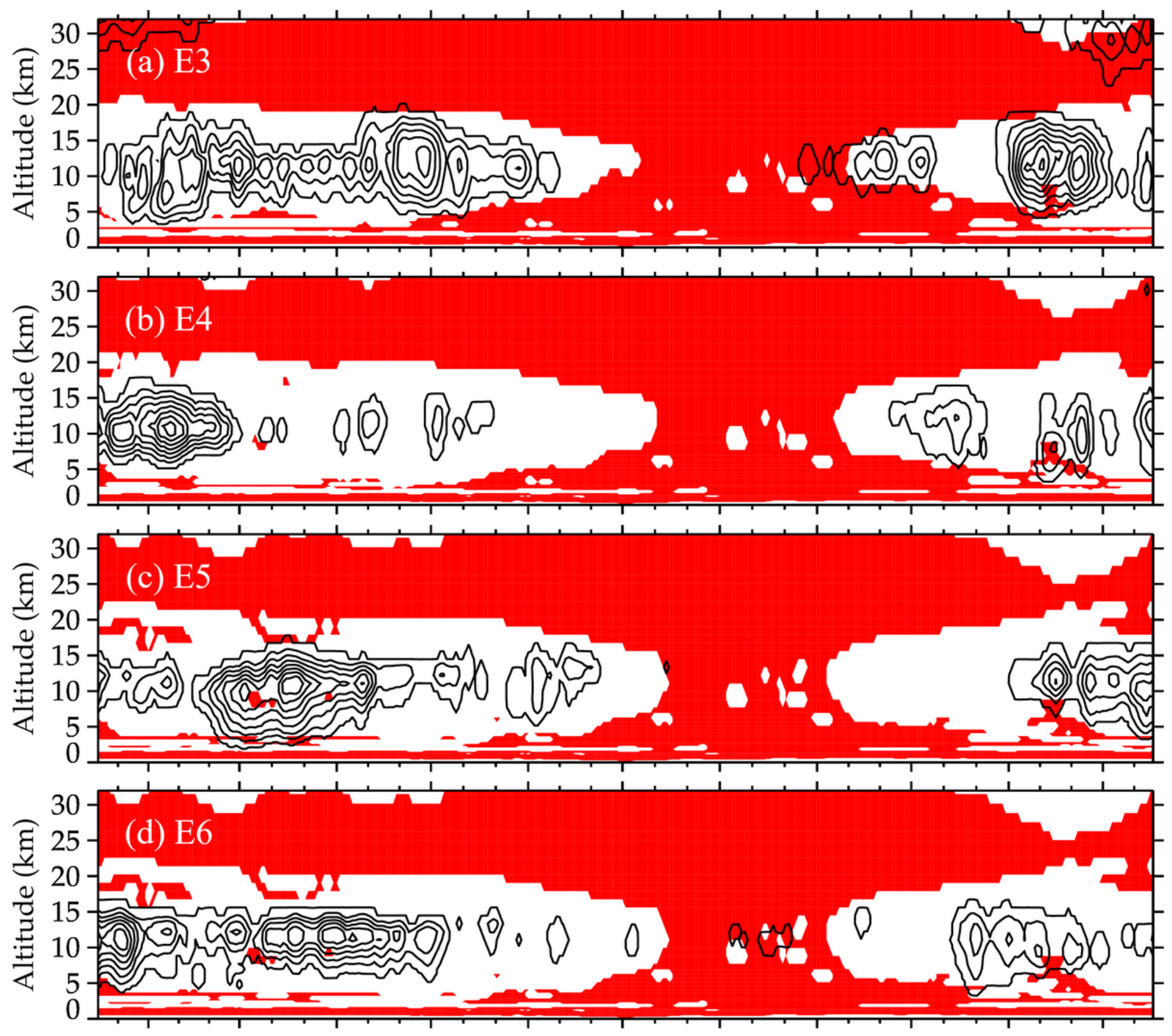

Feb. Mar. Apr. May Jun. Jul. Aug. Sept. Oct. Nov. Dec.

Figure 5

Time-altitude sections of the refractive index squared and zonal wind amplitudes of (a) E3 and (b) E4 and (c) E5 and (d) E6 10DWs at $32^{\circ} \mathrm{N}$ in 2020 . Regions with a negative refractive index squared are shaded in red, and the black contours denote the zonal wind amplitudes of the 10DW. Contours are from $2 \mathrm{~ms}^{-1}$ at an interval of $0.5 \mathrm{~ms}^{-1}$. 

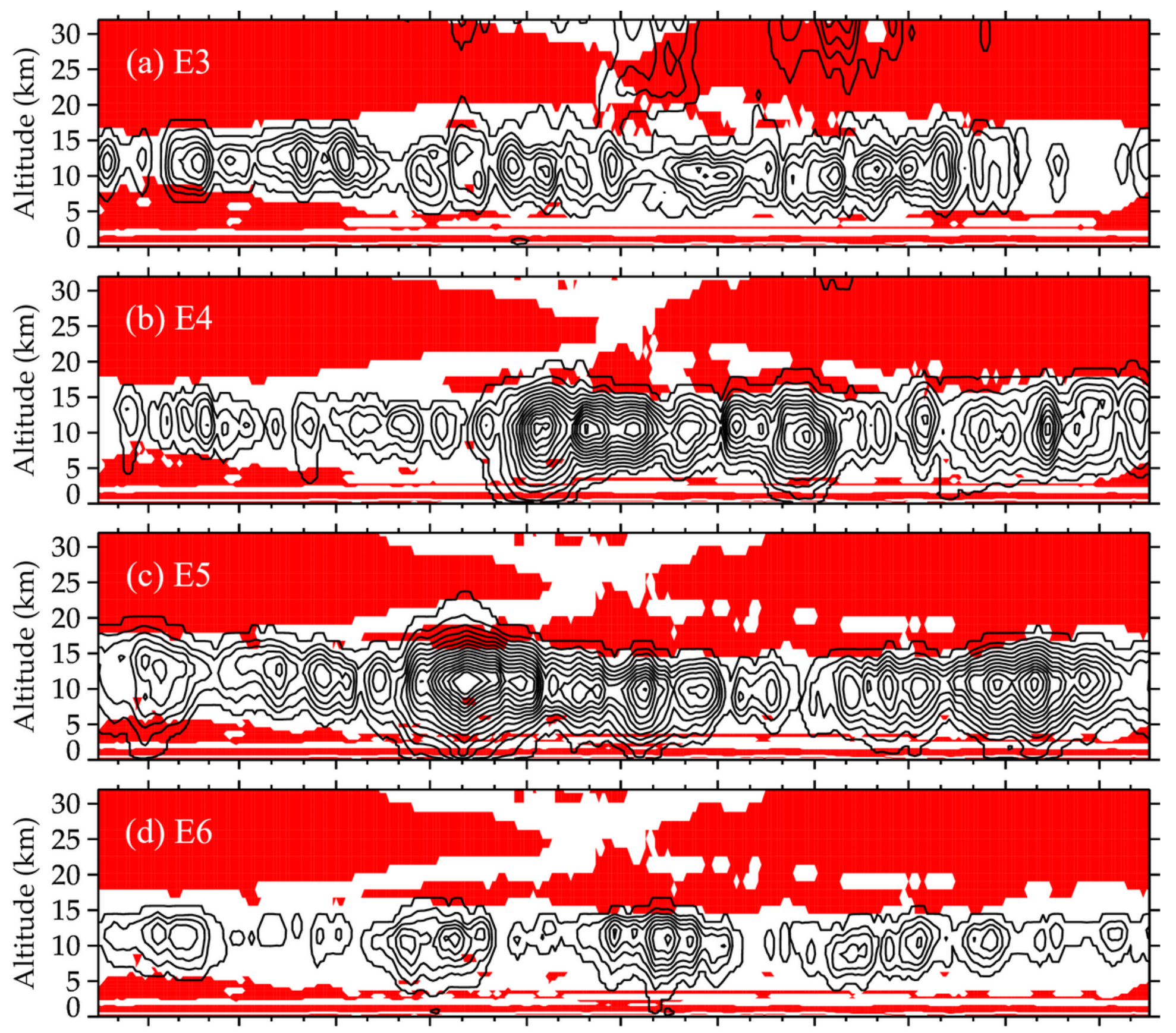

Feb. Mar. Apr. May Jun. Jul. Aug. Sept. Oct. Nov. Dec.

Figure 6

Time-altitude sections of the refractive index squared and zonal wind amplitudes of (a) E3 and (b) E4 and (c) $\mathrm{E} 5$ and (d) $\mathrm{E} 610 \mathrm{DWs}$ at $32^{\circ} \mathrm{S}$ in 2020 . Regions with a negative refractive index squared are shaded in red, and the black contours denote the zonal wind amplitudes of the 10DW. Contours are from $2 \mathrm{~ms}^{-1}$ at an interval of $0.5 \mathrm{~ms}^{-1}$. 


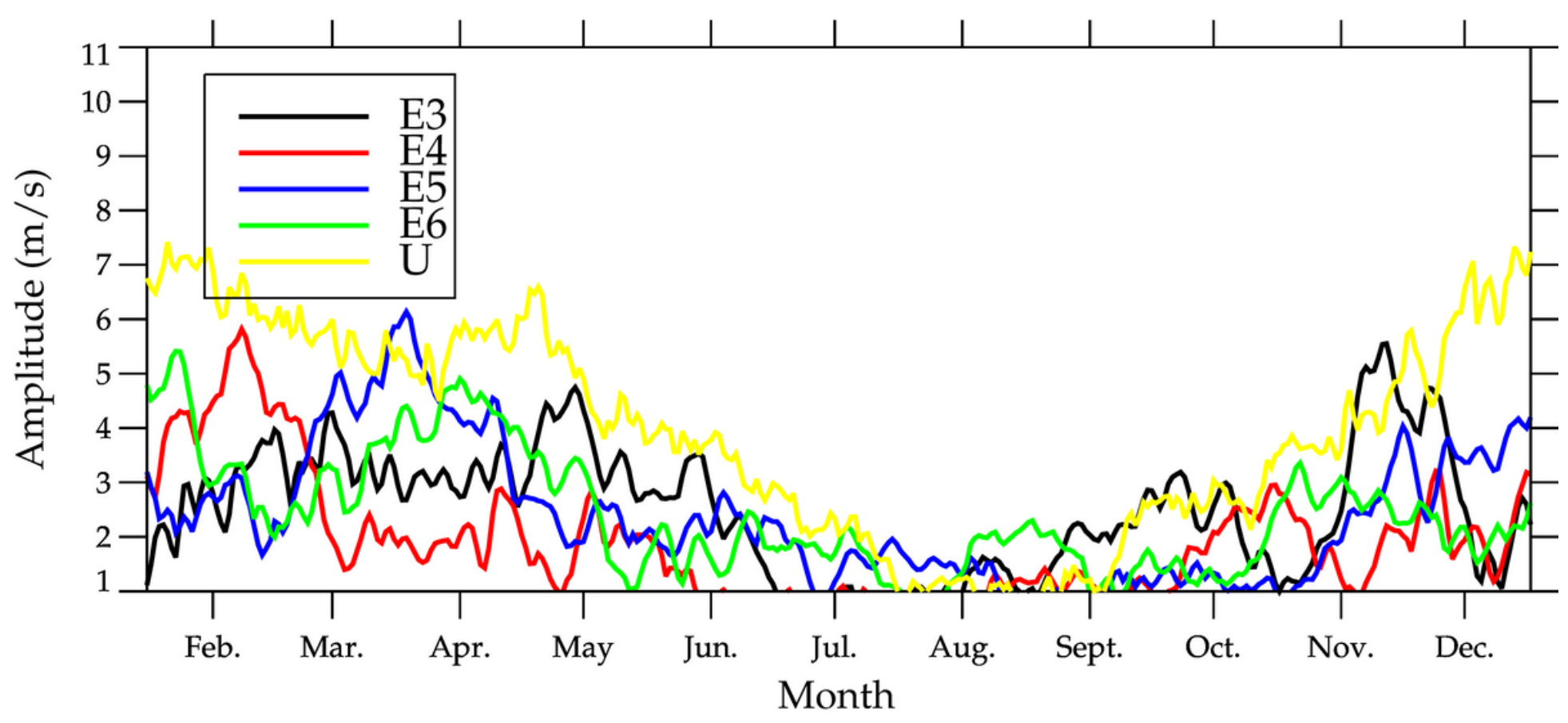

Figure 7

Zonal wind amplitudes of the 10-day eastward-propagating modes with zonal wavenumber 3 to 6 at $\sim 11$ $\mathrm{km}$ deduced from the MERRA- 2 data at $32^{\circ} \mathrm{N}$ in 2020. Yellow line marks the eastward zonal-mean zonal wind.

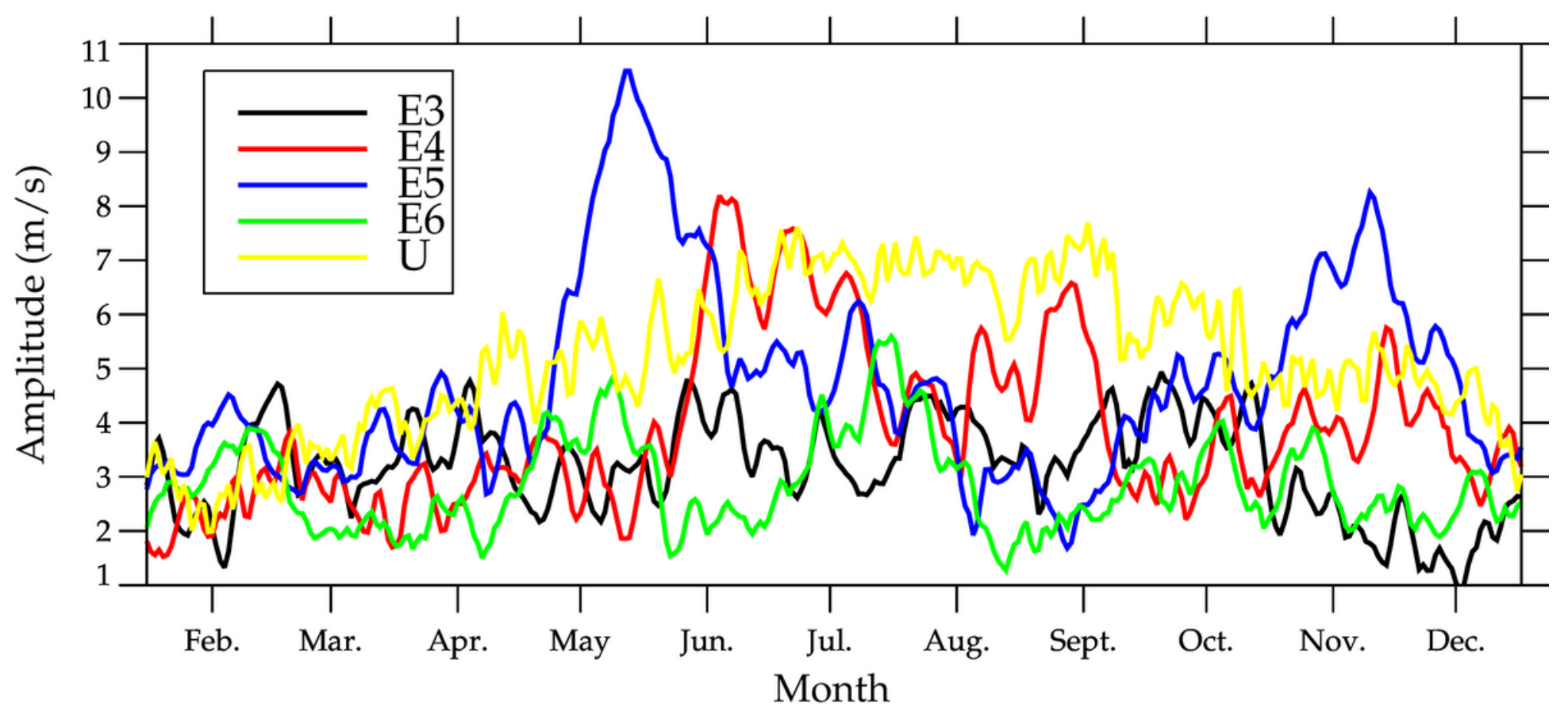

Figure 8

Zonal wind amplitudes of the 10-day eastward-propagating modes with zonal wavenumber 3 to 6 at $~ 11$ $\mathrm{km}$ deduced from the MERRA- 2 data at $32^{\circ} \mathrm{S}$ in 2020 . Yellow line marks the eastward zonal-mean zonal wind. 


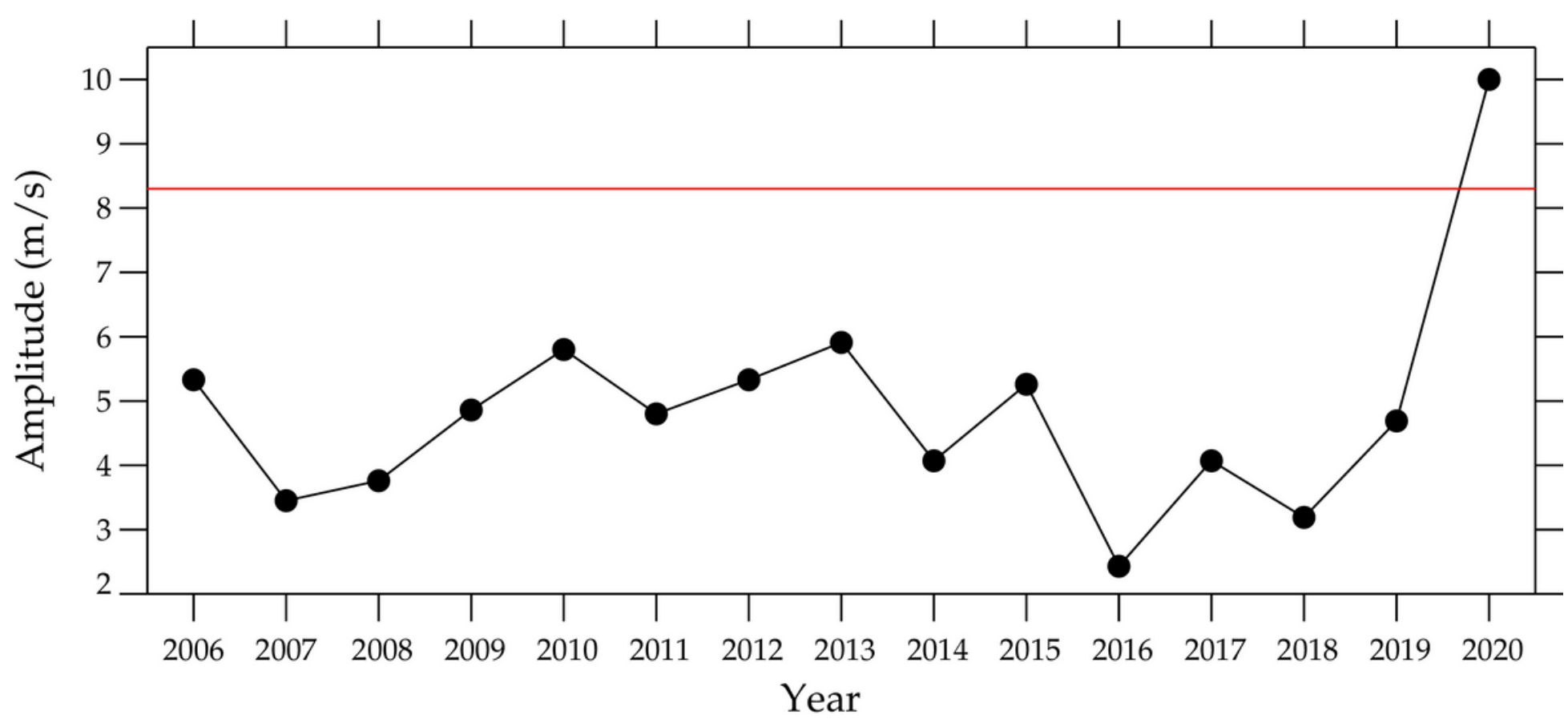

Figure 9

Results of the significance test. The black dots are the amplitudes of the E5 10DW at $32^{\circ} \mathrm{S}$ and $\sim 11 \mathrm{~km}$ on May 12 in each year from 2006 to 2020 . The red line is the climatological mean amplitude plus twice the standard deviation.

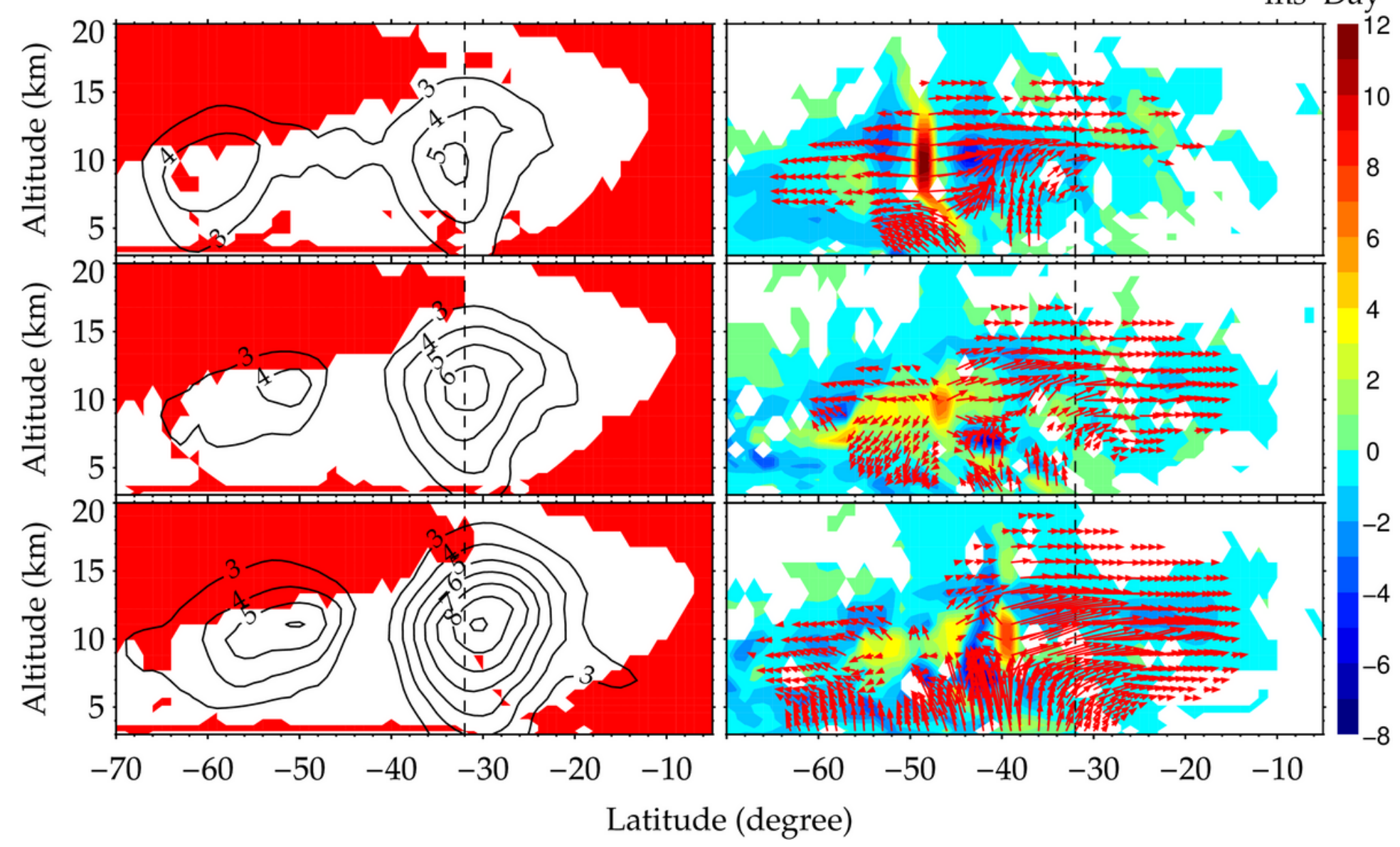


Figure 10

Latitude-altitude sections of the refractive index squared (left panels) and the EP flux (right panels) for the E5 10DW on April 24 (top row), April 30 (middle row) and May 6 (bottom row). In the left panels, regions with a negative refractive index squared are shaded in red, and the black contours denote the zonal wind amplitudes of the E5 10DW. In the right panels, regions with significant EP flux divergence or convergence are represented by colored contours, and the red vectors denote EPX and EPZ. The dashed vertical lines denote the latitude of $32^{\circ} \mathrm{S}$.

\section{Supplementary Files}

This is a list of supplementary files associated with this preprint. Click to download.

- GraphicalAbstract.png 